\title{
RELACIONAMENTO ENTRE PADRÕES DE DOENÇA E SERVIÇOS DE ATENÇÃO ODONTOLÓGICA
}

Vitor Gomes Pinto**

PINTO, V.G. Relacionamento entre padrōes de doença e serviços de atençăo odontologica. Rev. Saúde públ., S.Paulo, 23: 509-14, 1989.

RESUMO: Os serviços de assistência odontologica são analisados como uma das variáveis que condicionam os padrōes de doenças bucais de uma população. Outros fatores como o nivel sócio-econômico, condiçðes culturais, hábitos alimentares e o grau de desenvolvimento global de cada país usualmente exercem um papel bem mais representativo na determinação do nível de saúde de uma comunidade. É mostrada a situaçăo dramática dos países em desenvolvimento, os quais seguiram os modelos de prestação de serviços odontológicos e de formação de recursos humanos das naçōes industrializadas (grande número de profissionais que se dedicam a atender apenas as pessoas que podem remunerar os seus serviços), o que levou à ocorrência de índices crescentes de doenças bucais. Mostra que o principal desafio a ser vencido pela profissăo, nos dias atuais, $\boldsymbol{\epsilon}$ a construção de uma odontologia com conteúdo social, dirigida para todos.

DESCRITORES: Saúde bucal. Serviços de saúde bucal. Doenças da boca, epidemiologia.

A existência de serviços odontológicos é apenas uma das variáveis que condicionam os padrões de doenças bucais de uma populaçāo, e em geral não se situa entre as mais importantes.

Uma multiplicidade de variáveis extraodontológicas condiciona o surgimento das doenças e influi no ritmo da sua expansão. $O$ desenvolvimento económico, a forma de organização do governo, o nível educacional da população assim como os padrões de cultura e de tradição popular que regulam a formação de hábitos alimentares e as condutas de higiene pessoal e coletiva, fazem parte intima do processo saúdedoença.

A adequação dos serviços de saúde ao quadro epidemiológico predominante e aos problemas mais típicos de cada sociedade continua se constituindo num dos principais desafios a serem vencidos pelo mundo contemporâneo. Enquanto. as comunidades apresentam, cada uma, um conjunto específico de moléstias com níveis de gravidade e incidência igualmente particulares e fortemente condicionados pelos fatores ambientais $e$ pelos padrōes de renda locais, os serviços de saúde muitas vezes estão organizados segundo sua própria lógica, ofertando açőes de caráter eminentemente curativo, de preferencia situados nos grandes centros urbanos e com ênfase para as camadas de melhor poder aquisitivo.

Como se fossem dois sistemas independentes - as necessidades de atenção em saúde por um lado e o aparelho prestador de cuidados de outro - essas duas faces da mesma moeda passaram a trilhar caminhos distintos até atingir a situação hoje diagnosticada por exemplo na maior parte da América Latina, onde, apesar da disponibilidade de meios para o controle dos problemas de saúde bucal, a sociedade enfrenta níveis crescentes ou na melhor das hipoteses estacionários de doença.

O resultado é que, no mundo atual, as maiores concentraçóes de odontólogos ocorrem exatamente nos países cujas populações alcançaram, no presente ou no passado recente, os mais altos indices de ataque pela principal das doenças bucais: a cárie dental. Paradoxalmente, tem sido comum a constatação de uma sólida e economicamente próspera profissão convivendo com in dices muito altos de doenças bucais.

Analisando os diversos fatores que influenciam os padrőes de doenças orais, vejamos inicialmente dados referentes à disponibilidade de dentistas lado a lado com a prevalência da cárie dental aos doze anos de idade, níveis de renda e de

- Documento apresentado na "World Dental Conference - Bristol 88", em Bristol, Inglaterra - 7/9/88, durante o Painel inicial: "Setting The Scene-global aspects of oral health care

- Divisão Nacional de Saúde Bucal do Ministério da Saúde - Bloco 11 - Sala 313 - $3^{\circ}$ andar - 70058 - Braślia, DF - Brasil. 


\section{TABELA 1}

População, CPO-D, Produ to Nacional Bruto, suprimento de açúcar per capita, número de cirurgiōes-dentistas e pessoas por cirurgião-dentista, para países divididos pelo nivel de renda, 1981 e 1985

\begin{tabular}{rlccccccc}
\hline Ano & $\begin{array}{c}\text { Nível de } \\
\text { renda }\end{array}$ & $\begin{array}{c}\text { Número } \\
\text { de } \\
\text { países }\end{array}$ & $\begin{array}{c}\text { População } \\
\text { (em } \\
\text { milhões) }\end{array}$ & $\begin{array}{c}\text { CPO-D } \\
\text { médio } \\
12 \text { anos } \\
\text { de idade }\end{array}$ & $\begin{array}{c}\text { PNB } \\
\text { per } \\
\text { capita } \\
\text { (dólares) }\end{array}$ & $\begin{array}{c}\text { Suprimento de } \\
\text { Açucar per } \\
\text { capita (em } \\
\text { gramas por } \\
\text { dia) }\end{array}$ & $\begin{array}{c}\text { Número de } \\
\text { cirurgióes- } \\
\text { dentistas } \\
\text { (em mil) }\end{array}$ & $\begin{array}{c}\text { Pessoas } \\
\text { por } \\
\text { cirurgião- } \\
\text { dentista }\end{array}$ \\
\hline \multirow{2}{*}{1981} & Baixo & 45 & $2.606,7$ & 1,56 & 395 & 23 & 63,6 & 40.986 \\
& Médio & 22 & 478,7 & 4,84 & 2.088 & 104 & 180,2 & 2.656 \\
& Alto & 37 & $1.130,4$ & 3,79 & 8.838 & 108 & 513,7 & 2.200 \\
1985 & Baixo & 47 & $2.850,7$ & 1,72 & 365 & 28 & 75,0 & 38.009 \\
& Médio & 26 & 553,3 & 4,79 & 1.855 & 105 & 221,6 & 2.497 \\
& Alto & 37 & $1.168,1$ & 3,56 & 9.240 & 107 & 616,4 & 1.895 \\
\hline
\end{tabular}

Fontes: The Czamikow Sugar Review ${ }^{1}$; Demographic Yearbook: $1985^{2}$; FDI ${ }^{3}$; International Bank for Reconstruction and Development ${ }^{5}$; Ministério da Saú de ${ }^{6}$; Pinto, V.G. ${ }^{7}$; S tatistical Bulletin ${ }^{10,11}$; WHO ${ }^{12}$

TABELA 2

CPO-D, pessoas por cirurgião-dentista e PNB per capita para 110 paises divididos por regiões,com dados de 1987

\begin{tabular}{lccc}
\multicolumn{1}{c}{ Região } & $\begin{array}{c}\text { CPO-D médio aos } \\
12 \text { anos de idade }\end{array}$ & $\begin{array}{c}\text { Pessoas por cirur- } \\
\text { gião-Den tista }\end{array}$ & $\begin{array}{c}\text { PNB per capi ta } \\
\text { (em dólares) }\end{array}$ \\
\hline África e Ãsia & 2,19 & 36.866 & 531 \\
África & 2,01 & 30.250 & 735 \\
Ásia & 2,23 & 38.470 & 490 \\
Ásia - Média e Alta Renda & 2,99 & 9.438 & 3.382 \\
Ásia - Baixa Renda & 2,18 & 47.760 & 324 \\
América Latina & & & 1.807 \\
América do Sul & 5,64 & 2.072 & 1.750 \\
América Central e Caribe & 5,73 & 1.745 & 1.956 \\
Países Industrializados & 5,40 & 3.325 & 8.700 \\
Europa Ocidental & 3,64 & 1.839 & 8.430 \\
Europa Oriental & 3,75 & 1.673 & 4.141 \\
Pá́ses não Europeus & 3,50 & 2.150 & 13.630 \\
\hline
\end{tabular}

Fontes: The Czarnikow Sugar Review ${ }^{1}$; Demographic Yearbook: $1985^{2}$; FDI ${ }^{3}$; International Bank for Reconstruction and Development ${ }^{5}$; Pinto, V.G. ${ }^{7}$; WHO ${ }^{12}$.

consumo individual de açúcar.

Na Tabela 1 temos dados relativos a 104 países em 1981 e a 110 países em 1985, distribuidos de acordo com níveis de renda per capita: baixa renda - produto nacional bruto de no máximo mil dólares; renda média - entre mais de mil até três mil dólares e alta renda com mais de três mil dólares. Não aconteceram modificações significativas nos diversos índices neste intervalo. Em 1985, por exemplo, temos que o grupo de naçóes de baixa renda, com cerca de $62 \%$ da população mundial, dispunha de cerca de $8 \%$ dos odontólogos e os mais baixos níveis de cárie dental e de consumo de açúcar. No polo oposto, os países de alta renda com $26 \%$ da população concentravam $68 \%$ dos profissionais, apreséntando índices decrescentes de ataque pela cárie dental desde meados da década passada $1,3,5,11,12$. Pouco mais de um décimo da população e um quarto dos dentistas estavam no mundo em desenvolvimento - onde tambem estavam os mais altos índices de cárie dental e de ingestão de açúcar.

$\mathrm{Na}$ Tabela 2 são mostradas relaçőes habitantes/dentista para a África, Ásia, América Latina e países industrializados junto com o índice CPO-D e o PNB per capita. As mais dramáticas condiçōes em termos de oferta de serviços odontológicos são encontradas no grupo de países asiáticos de baixa renda onde estima-se que em 1985 existiam 47.760 pessoas para cada dentista. Contudo, o seu indice CPO-D estava entre os męnores do globo - 2,18 dentes atacados por 
TABELA 3

Suprimento diário médio de açúcar per capita em gramas, por regiões no mundo - 1975, 1980 e 1985

\begin{tabular}{lrrr}
\hline & \multicolumn{3}{c}{ Suprimento diário de açucar } \\
\cline { 2 - 4 } & 1975 & 1980 & 1985 \\
\hline África & 35,1 & 39,4 & 42,2 \\
Ásia & 19,2 & 23,3 & 30,7 \\
Oceânia & 133,1 & 128,2 & 119,8 \\
América do Sul & 111,2 & 125,7 & 109,1 \\
América Central & 110,7 & 116,2 & 124,9 \\
América do Norte & 116,2 & 112,6 & 86,3 \\
Europa & 106,0 & 112,9 & 113,9 \\
Mundo & 51,8 & 54,8 & 57,0 \\
\hline
\end{tabular}

Fonte: The Czarnikow Sugar Review ${ }^{1}$; Statistical Bulletin ${ }^{10,11}$

TABELA 4

Produção mundial de açúcar e consumo de 1985 a 1988 no mundo, por regiôes

\begin{tabular}{|c|c|c|c|c|c|c|c|c|}
\hline \multirow{2}{*}{ Regiāo } & \multicolumn{4}{|c|}{ Produção (em mil toneladas) } & \multicolumn{4}{|c|}{ Consumo (gramas por dia) per capita } \\
\hline & 1985 & 1986 & 1987 & 1988 & 1985 & 1986 & 1987 & 1988 \\
\hline Africa & 7.998 & 8.291 & 8.422 & 8.699 & 42,2 & 41,8 & 40,5 & 40,1 \\
\hline Ásia & 34.466 & 31.369 & 33.981 & 35.193 & 30,7 & 30,2 & 31,4 & 31,2 \\
\hline Oceânia & 1,006 & 1.064 & 1.070 & 1.080 & 119,8 & 121,5 & 118,7 & 115,9 \\
\hline América do Sul & 10.756 & 11.505 & 11.800 & 11.597 & 109,1 & 113,8 & 113,0 & 107,6 \\
\hline América Central & 6.066 & 5.900 & 6.121 & 6.243 & 124,9 & 117,1 & 116,5 & 114,8 \\
\hline América do Norte & 8.340 & 8.154 & 8.502 & 8.631 & 86,3 & 82,4 & 84,1 & 83,3 \\
\hline Europa & 34.078 & 34.977 & 35.348 & 35.621 & 113,9 & 116,1 & 116,5 & 116,7 \\
\hline Mundo & 98.710 & 101.260 & 105.244 & 107.063 & 57,3 & 56,3 & 56,5 & 55,6 \\
\hline
\end{tabular}

Fonte: The Czarnikow Sugar Review ${ }^{1}$; Demographic Yearbook: $1985^{2}$; Pin to, V.G. ${ }^{7}$; Statistical Bulletin ${ }^{10,11}$

criança aos 12 anos - só sendo superado pela África.

Um leigo poderia perguntar porque na Etiópia, o país com a mais baixa renda per capita mundial (110 dólares anuais), as crianças não têm cáries, enquanto que na Alemanha Ocidental (10.940 dolares per capita) a doença causa tanto sofrimento $^{5,12}$. A resposta nós a conhecemos: a cárie dental não é uma "doença da pobreza" como as enfermidades transmissíveis e a desnutrição, por exemplo; e sim uma conseqüência do desenvolvimento, o qual costuma apresentar como um dos seus efeitos perversos um ativo incremento nos padrões de consumo de açúcar. $O$ desenvolvimento econômico também traz consigo os odontólogos, mas estes não são capazes de impedir a instalação e a expansão da doença porque se dedicam quase que exclusivamente à prestação de serviços curativos e a atender a quem pode pagálos.

O comportamento de um dos principais fatores condicionantes do processo cárie - o consu- mo de açúcar - está nas Tabelas 3, 4 e 5. Os dados referem-se à disponibilidade de açúcar, correspondendo em cada país ao açúcar de cana ou de beterraba produzido mais as importações e menos as exportaçōes, dividido pela população.

De acordo com a Tabela 3 observamos que houve um aumento de aproximadamente $10 \%$ no consumo mundial de açúcar entre 1975 e 1985 . Os mais significativos aumentos aconteceram na Ásia com $60 \%$ e na África com $20 \%$, ou seja, nas regiōes até então mais isentas de cárie. Afortunadamente houve tamberm importantes diminuições no consumo, destacando-se os $22 \%$ de redução obtidos na América do Norte.

Estimativas de consumo para o período atual - 1985 a 1988 na Tabela 4, mostram um ligeiro descenso global, embora a tendéncia ao aumento prossiga na Ásia e na Europa. A produção mundial aumentou continuamente, mas nos últimos três anos não conseguiu acompanhar o ritmo de crescimento populacional.

Finalmente, a Tabela 5 indica os principais 


\section{TABELA 5}

Estimativa da produção mundial de açúcar: principais produtores em 1988

\begin{tabular}{lr}
\hline $\begin{array}{l}\text { Produção de açucar (de cana ou beterraba - em mil } \\
\text { toneladas }\end{array}$ \\
\hline 1. Mercado Comum Europeu & 14.016 \\
2. União Soviética & 9.855 \\
3. India & 9.500 \\
4. Brasil & 8.545 \\
5. Cuba & 7.350 \\
6. Estados Unidos da América & 5.740 \\
\multicolumn{2}{c}{ Mundo } \\
\hline
\end{tabular}

Fontes: The Czarnikow Sugar Review ${ }^{1}$; Pinto, V.G. ${ }^{8}$; Statistical Bulletin $1 \mathrm{f}$

produtores de açúcar no mundo: Mercado Comum Europeu, URSS, Brasil, Cuba e EUA, responsáveis por $51,4 \%$ da produção mundial no ano 1987/88. No Mercado Comum Europeu, a França e a Alemanha Ocidental lideram as estatísticas produzindo em conjunto metade do total.

Pelo menos ao longo da próxima década tudo indica, portanto, que os padrőes internacionais de produção e ingestão de açúcar - 0 arquiinimigo dos odontólogos - permanecerão altos no mundo desenvolvido e em desenvolvimento, além de crescerem nas regiōes economicamente mais deprimidas.

Caso não consigamos inverter estas tendências, é praticamente certo que os povos de vastas áreas na África e na Ásia sofrerão altos índices de cárie à medida em que progrediram economicamente.

Tradicionalmente, o incremento na disponibilidade de dentistas e o fortalecimento da classe odontológica tem sido uma conseqüência de altas prevalências de cárie dental, pois esta apresenta uma fase aguda em geral acompanhada pela dor.

Quanto às doenças periodontais, crônicas por excelência, elas só têm conseguido motivar a presença de dentistas junto às faixas de alta renda, junto à elite social. Os exemplos das comunidades indígenas latino-americanas e de muitos povos asiáticos e africanos são reveladores: com poucas cáries e altos niveis de doenças periodontais, quase desconhecem os odontólogos.

De fato, as doenças periodontais - que afetam a humanidade de maneira significativa desde a mais remota antiguidade - so ganharam status a partir do momento em que, nos países mais industrializados, foi possível manter a cárie dental sob controle. Nesses países, a profissão odontológica passou a necessitar de um "novo" motivo ou uma "nova" enfermidade de massa para justificar os seus serviços, a manutenção da clientela e, enfim, a sua própria existéncia.

\section{TABELA 6}

Percentual de pessoas com tártaro ou bolsas profundas segundo o valor mais alto do índice comunitário de necessidades de tratamento periodontal, percentual sem doenças periodontais, İndice Físico de Qualidade de Vida (IFQV) e Produto Nacional Bruto (PNB) per capita em países selecionados.

\begin{tabular}{lccccc}
\hline País & $\begin{array}{c}\text { \% com } \\
\text { tártaro }\end{array}$ & $\begin{array}{c}\text { \% com bolsas } \\
\text { profundas }\end{array}$ & $\begin{array}{c}\text { \% sem doenças } \\
\text { periodontais }\end{array}$ & $\begin{array}{c}\text { Indice Físico } \\
\text { de Qualidade } \\
\text { de Vida * }\end{array}$ & $\begin{array}{c}\text { PNB per capita } \\
\text { (em dólares) }\end{array}$ \\
\hline Espanha & 36 & 18 & 7 & 7 & 4,290 \\
Indonésia & 36 & 10 & 0 & 58 & 530 \\
Grécia & 39 & 14 & 8 & 92 & 3,550 \\
Brasil & 40 & 5 & 5 & 73 & 1,640 \\
Tailândia & 42 & 16 & 0 & 99 & 800 \\
Japão & 44 & 7 & 7 & 95 & 11,300 \\
Itália & 45 & 12 & 3 & 33 & 6,250 \\
Nepal & 45 & 28 & 0 & 47 & 160 \\
Marrocos & 45 & 14 & 4 & 86 & 560 \\
Portugal & 47 & 8 & 3 & 1.970
\end{tabular}

* O IFQV é uma média nacional de três componentes: mortalidade infantil, esperança de vida com 1 ano de idade e alfabetização. Seu valor máximo é 100 e o mínimo zero.

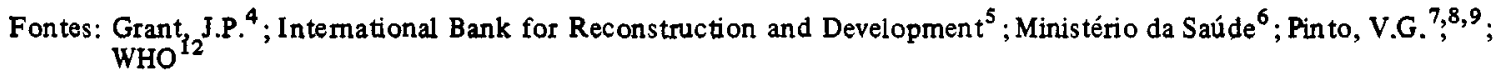


Vale a pena referir que ainda não dispomos de um padrão internacional definido para a ocorrência das doenças periodontais, as quais com freqüência apresentam índices parecidos em populações com tradiçōes e níveis econômicos muito distintos entre si.

A Tabela 6 mostra o percentual de pessoas com tártaro, bolsas profundas e sem doenças periodontais, junto com o f́ndice material de qualidade de vida e a renda per capita em dez países selecionados. Os países guardam similaridade apenas em relação à primeira coluna (pessoas com tártaro), variando fortemente nos outros quatro indicadores, numa demonstração clara das dificuldades que hoje ainda temos para compreender o processo periodontal. Mas, de todas as maneiras, parece claro que o combate às doenças periodontais deve ser dado tanto na Itália e no Japão, quanto no Nepal e na Indonésia.

No mundo em desenvolvimento, o atual conjunto de unidades de assistência odontológica, notadamente no setor público, surgiu de maneira gradativa a partir de dois condicionantes principais: a pressāo por empregos das corporações profissionais que são grupos mais bem estruturados dentro da sociedade e a inevitabilidade de proporcionar um mínimo de serviços para atender d̀ demanda real por parte das camadas populacionais de baixa renda. A finalidade deste "nãosistema" é satisfazer parcialmente os grupos de pressão mais fortes e impedir que a situação epidemiológica se agrave ao ponto de criar novos focos de crise social. O resultado é que as doenças bucais após terem atingido um patamar elevado ou muito elevado, mantém-se sem alterações num limite de equilíbrio instável onde a população, assoberbada por outras tantas dificuldades de maior relevância vital, parece considerar os problemas bucais - a cárie dental e as doenças periodontais seguidas pelas extrações e pela prótese - como uma fatalidade inevitável ou uma contingência natural ligada à carência financeira.

Há, em conseqüência, uma ampla liberdade para adoecer e para assistir a evolução da doença até que ela se torne fisicamente não suportável. Nesse estágio terminal do processo, a exigir em geral a ação profissional especializada, também os custos tornam-se insustentáveis para o indivíduo e para as nações em đesenvolvimento.

Sempre que um país, uma região ou uma localidade optar pela ênfase na assistência curativa e sempre que um serviço ou programa limitar seus objetivos a proporcionar empregos, a melhoria das condições de saúde da comunidade tor- na-se uma meta virtualmente impossível a ser atingida.

Devemos, ainda, considerar a presença de fatores adversos diretamente ligados aos próprios serviços odontológicos. Não basta possuir serviços odontológicos em quantidade suficiente e razoavelmente bem distribuídos. É preciso, também, que estejam corretamente organizados e que possuam fontes de financiamento sólidas e perenes para que de fato beneficiem a população.

Serviços odontológicos perdem muito em eficácia quando são prestados em moldes tradicionais, ou seja, proporcionando cuidados curativos por livre demanda a problemas já instalados.

Das três formas básicas de organização da prática odontológica - privada ou liberal; indireta ou privatizada e direta ou assalariada - as duas primeiras têm sido as preferidas, pelo menos no mundo ocidental.

O regime liberal, baseado nas leis de mercado, costuma ser o preferido pelos profissionais, mas só se aplica às pessoas que podem remunerar os serviços que thes são prestados. Nos países não desenvolvidos economicamente, essas pessoas formam uma minoria - entre 10 e $30 \%$ da população e é impossível pensar em sua universalização 5 .

Já os serviços prestados indiretamente (em geral financiados por instituiçoes de seguro social e executados por dentistas em seus próprios consultorios) apresentam custos mais altos devido à intermediação de um terceiro personagem entre o paciente e o profissional, costumam ter forte ênfase curativa e estão muito sujeitos a fraudes. Não obstante alguns países industrializados tenham obtido resultados satisfatorios em termos de atenção curativa à populaçăo utilizando esses dois modelos, tanto os serviços liberais como os privatizados não têm sido capazes de transformar favoravelmente o quadro epidemiológico no mundo em desenvolvimento.

A modalidade direta, de trabalho assalariado, é a que menos discrimina a clientela, sendo teoricamente a mais universalizável desde que 0 país ou região tenha um adequado programa de ação e recursos suficientes para implementar serviços com a amplitude necessária.

Seguindo esta mesma linha de raciocínio, pode-se dizer que das três principais modalidades de financiamento de serviços odontologicos - tributos, descontos sobre a folha de salários e pagamento direto pelas pessoas - a primeira (tributo) é a mais compatível com um programa de larga cobertura populacional. 
Concluindo, destacamos dois pontos:

a) A experiencia tem mostrado que o espaço de influência do setor saúde em seu todo e da odontologia em particular é menor sob governos não democráticos onde o Estado limita-se a açōes paliativas no campo social, impedindo que se cumpram atividades de importância fundamental como a organização da população para participar e apoiar o programa de saúde, temeroso de que as reuniōes populares tragam d tona a discussão dos problemas econômicos e sociais básicos, desafiando o seu domínio.

b) A asfixiante crise econômica hoje vivida pelo mundo em desenvolvimento - estima-se a divida externa total em pelo menos 803 bilhões de dólares de acordo com dados đo Banco Mundial para $1985^{5}$ - impede-o de aumentar os gastos com serviços sociais e conseqüentemente com a saúde bucal.

Enfrentar estes dilemas, superar estas contradiçőes, constitui o grande desafio para a odontologia nos dias atuais. Já demonstramos que é possivel mudar o quadro epidemiológico em situaçóes mais favoráveis como as dos países industrializados. Cabe-nos agora construir uma odontologia com conteúdo social, dirigida para todos e nåo somente para alguns, nos países economicamente débeis.

PINTO, V.G. [Relationship between disease patterns and oral care services]. Rev.Satade públ, S.Paulo, 23:509-14, 1989.

ABSTRACT: Oral care services are examined as one of the variables related to the oral disease patterns of a population as well as other factors such as social and economic level, culture, nutrition patterns and the degree of global development of each country which play a more important role in determining the level of health in the community is analysed. The dramatic situation in the developing countries, which have emulated the oral care services and human resources training models of industrialized countries (large numbers of professionals who render services only to those who can pay for them), which have led to an increasing prevalence of oral diseases, is described. It shows that the main challenge to the profession at the present time is the building up of dental services rooted in social issues and aimed at the population at large.

KEYWORDS: Oral health. Dental care. Month diseases, epidemiology.

\section{REFERENCLAS BIBLIOGRAFICAS}

1. THE CZARNIKOW SUGAR REVIEW. London, (1770) Feb. 1988.

2. DEMOGRAPHIC YEARBOOK: 1985. (United Nations) New York, 1987.

3. FÉDÉRATION DENTAIRE INTERNATIONAL (FDI). World siruation regarding dental manpower: tables by country. London, 1988.

4. GRANT, J.P. Disparity reduction rates in social indicators: a propasal for measuring and targeting progress in meeting basic needs. Washington, D.C., 1978.

5. INTERNATIONAL BANK FOR RECONSTRUCTION AND DEVELOPMENT. World development report, 1978. Washington, D.C., 1987.

6. MINISTÉRIO DA SAÚDE. Divisåo Nacional de Saude Bucal. Levantamento epidemiologico em saúde bucal: Brasil, zona urbana, 1986. Brasilia, 1988.

7. PINTO, V.G. Global indicators of changes in oral health -
April/1984 - DMFT, GNP, PQLI, Sugar Supply in 104 countries. Braslia, IPEA, 1984. [Trabalho apresentado ao Joint Working Group WHO/FDI, 5].

8. PINTO, V.G. Saude bucal odontologia social e preventiva. Såo Paulo, Ed. Santos, 1989.

9. PINTO, V.G. Saúde bucal: panorama intemacional Brasilia, Ministério da Saude, 1990. [No prelo]

10. STATISTICAL BULLETIN. (International Sugar Organization). London, 44(6) June, 1985.

11. STATISTICAL BULLETIN. (International Sugar Organization). London, 47(5) May, 1988.

12. WORLD HEALTH ORGANIZATION. Oral dental health global indicators for 2000, DMFT 12 years. Geneva, 1988.

Recebido para publicaçäo em 22/5/1989 Aprovado para publicação cm 15/8/1989 